\title{
The future of educational research: has Nietzsche led the way?
}

A peculiar and persistent feeling of enervation accompanies and describes a certain, rapidly predominating place; a place that is an end; the very end; the end of hope; the termination of difference; the triumph of fear; the automatic capitulation of one's own and others' being; but most depressingly of all, it is a dreadful place, because it is an end without end. This is a place that is almost featureless; a place that is almost empty, and yet claustrophobic; a place that is reductive, isolated, and inescapable; a place that is determined to forge everything fated to be caught within its limiting space, into its own precisely narrow identity of sparse functionalism. This place is what education, particularly state education, since state schooling led the way, has become. And unsurprisingly, perhaps even predictably, with little or no resistance, this is what educational research has developed into; predominantly, as the state's supporting mechanism. But worse: for some time, and quite desperate not to see its own shame, this has become, overwhelmingly, the uncritical, blind concern, the stark, empty, dismal future, of educational research.

As an indication of this condition, we need only refer to the research published in a recent edition of a leading educational research journal, namely the British Educational Research Journal, Feb2016, Vol. 42 Issue 1. The papers include: 'Do mothers' and fathers' work involvement matter for teenagers' school outcomes?'; 'Realising and extending Stenhouse's vision of teacher research: the case of English history teachers'; 'Teacher shortage and attrition: Why do they leave?'; 'Studying while doing time: understanding inmates' conceptions of learning'; 'A pedagogy of conceptual progression and the case for academic knowledge'; 'Framing the geographies of higher education participation: schools, place and national identity'; 'Marginal groups in marginal times: Gypsy and Traveller parents and home education in England, UK'; 'Reassessing the economic value of advanced level mathematics'; 'Classroom segregation: where do students sit and how is this related to group relations?'; 'Staying on-track despite the odds: Factors that assist young people facing adversity to continue with their education'. Clearly, and this characteristic is integral to what has become the endlessly morbid fate of the nature of the educational research which has come to define the gathering entropy of its limiting space, it would be impossible to suggest that in any way, any of these papers, and the enterprise more generally that they represent, was anything other than of the highest standard. Each has managed to win its place, in terms of its research excellence, in a very competitive market, which is precisely what publication in the British Educational Research Journal represents. A highly rigorous process of peer review insures the quality of this outcome, according to two guiding principles, those of relevance and impact. Let us think about what this means, for a moment. Given that state schooling has for some time in its neoliberal incarnation seen its driving force as the provision of an equally accessible bank of skills and forms of knowledge that provide access for the recipients to an open market of opportunities to compete for their own progressive betterment and independence; relevance in this context means in some way contributing towards the ever greater operating efficiency of this same educational regime. Of course, that relevance of educational research might impact, with impact being the second of the guiding principles that have come to define the fate of educational research, on the operational efficiency of neoliberal state educational machinery in many varied ways. For example, excellent research that sought to understand whether or not the amount of time that parents spent away from their children because of an imperative, a neoliberal imperative, that drove them to occupy more of their lives earning more money, this had an impact on the educational outcomes of their children, might be able to indicate the optimal amount of time that a parent could spend away from their children to increase their economic well-being without having a negative impact on the educational attainment of their offspring. Such research, in this very same context, is inherently relevant, in that it contributes not only to increasing the efficiency of the neoliberal educational regime, by, for example providing 
useful information to those responsible for developing and implementing policy, areas that are themselves operationalised by the goal of increasing the efficiency of the system; but perhaps more importantly, such studies provide the neoliberal education system with knowledge about itself, in a classically liberal-humanist, self-reflexive, educational research mode. Knowledge of itself, as far as education in this context is concerned, is limited to an economy of improvement and competition. And this to the extent that, all issues pertaining to education are inflected through its lens of the educational becoming of the neoliberal subjects which this form of education strives to forge, and in which its own being is invested. Thus, the excellent paper by Rosario, et al (2016), a study of inmates' learning experiences in a male Portuguese prison sees the learning that takes place and its motivations in terms of education's transformative potential, the same educational transformative potential that failed to transform the subjects of the study originally into normatively educated subjects, and which, when generally translated into a penal context has historically - whilst having individually produced some spectacular results - tended overwhelmingly to have overall extremely marginal transformative success. Whilst other perspectives might be interested in how and why education is implicated in this process, educational research tends not to be able to see these and other questions because its consciousness has been developed around relevance and impact. And Rosario, et al's (2016) paper is an excellent paper.

It is in this context the imperative of the pursuit of relevance that guarantees the exclusive nature of the space through which educational research operates; a space that is therefore highly limited and is held in place by it being relentlessly policed and inspected in order to prevent any deviance from the regimes of performativity that characterize state schooling. This policing and inspecting is, of course, not simply an intellectual matter; indeed, other perspectives might suggest that such a division, in its classically Cartesian form, between thought, and its situated cultural and corporeal emergence, may be useful but is nevertheless a contingent understanding of the experience of human being; the policing and inspecting that hold this educational space in place are fundamentally political and exist and are experienced as practices and their affects. There are obvious examples of this, including Ofsted (the Office for Standards in Education, a government body, which is tasked amongst other things with undertaking the incessant inspection regime to which state schools and other educational institutions in England), and the performative frameworks that inhabit school and teacher effectiveness evaluations, pupil progress, educational attainment and curriculum content; but it is the construction of what constitutes educational knowledge within this context, in brutal economic terms, that there is no other space available to inhabit, that is the most implacable of its outcomes. The state and its education has organized itself so that no alternative to the inevitable marketisation of itself and what its education has become, seems to be available.

The option of eschewing this sate of affairs, of conceiving of educational research and of education in some other alternative way, seems to be no real alternative option at all; and also has the flavour of running away from the version of educational research and education now that we now face. Educationalists might want an alternative to the neoliberal state model with its attendant economy of competition and improvement, which is itself interesting, but no other state model is operating. And the endless chronicling of unfulfilled desire is ultimately also a poorly fulfilling project. Perhaps instead it is time not to think of alternatives, which are any way largely unavailable, but to embrace, in Nietzschean terms, one's fate, as it is equally ineffective to hope for the abandonment of the existence of this future of educational research and what it represents. In a thoroughly Nietzschean vein, we might ask, for example, what does current educational practice and experience represent for the marginalised and impoverished within society? What power is exercised and what forms of morality are at play in this educational arrangement? How does cultural, economic, situated corporeal experience educate us in relation to our identity, and through this our relations with the 
rest of the world? Such a view of educational research would, of course, extend the space beyond its currently defined narrow dimensions. For that reason, such a future is unlikely to occur. And perhaps that is the uncomfortable but nakedly political point. 